\title{
ABDOME AGUDO PERFURATIVO POR CORPO ESTRANHO EM PACIENTE COM SITUS INVERSUS TOTALIS
}

\section{Perfurative acute abdomen due to foreign body in patient with situs inversus totalis}

\author{
André Vitorio Câmara OLIVEIRA, Carlos Eduardo Costa MARANHÃo, Clístenes Dejane Sobral COELHO, \\ Sabine de Lucena Martins FERREIRA, Bruno Nogueira Bezerra TAVARES, Larissa Cavalcanti BARROS
}

\begin{abstract}
ABCDDV/628
Oliveira AVC, Maranhão CEC, Coelho CDS, Ferreira SLM, Tavares BNB, Barros LC. Abdome agudo perfurativo por corpo estranho em paciente com situs inversus totalis. ABCD Arq Bras Cir Dig 2008;21(4): 215-7

RESUMO - Introdução - Situs inversus totalis é descoberta importante para a conduta clínica cirúrgica. Corpo estranho no intestino grosso pode ocorrer devido a ingestão ou introdução anal. A perfuração intestinal é acompanhada de elevada morbidade e constitui-se em desafio aos cirurgiões. Relato do caso - Paciente, masculino, 28 anos, deficiente mental, com dor e distensão abdominal há sete dias, anorexia há dois, parada de eliminação de gases e fezes, sem vômitos. Ao exame apresentava dispnéia leve, desidratação (++/4++), PA=70X40mmHg, anictérico, abdome tenso, difusamente doloroso, distendido e hipertimpânico, ruídos hidroaéreos ausentes. A radiografia de tórax evidenciou dextroversão cardíaca, pneumoperitônio bilateral com bolha gástrica à direita. Devido ao estado geral grave e diagnóstico confirmado de abdome agudo perfurativo, realizou-se reposição hidroeletrolítica venosa e foi submetido à celiotomia exploradora, onde evidenciou-se peritonite fecalóide difusa e perfuração de cólon sigmóide por corpo estranho. Realizaram-se retirada do corpo estranho, limpeza mecânica, ampla lavagem da cavidade peritoneal, retossigmoidectomia à Hartmann e drenagem bilateral. Conclusão - Apesar de ser entidade rara, o diagnóstico de situs inversus totalis deve ser suspeitado durante o exame físico e confirmado através de exames de imagem, uma vez que as variações anatômicas podem prejudicar o desempenho clinicocirúrgico. DESCRITORES - Situs inversus. Perfuração intestinal.
\end{abstract}

\section{INTRODUÇÃO}

Situs inversus totalis (SIT) é achado pouco frequente, constituindo-se de descoberta importante para a conduta clínica cirúrgica².

Segundo Melchor-Gonzáles et al. ${ }^{7}$, a incidência varia de $0,002 \%$ a $1 \%$. A etiologia específica ainda não foi estabelecida, mas acredita-se estar relacionada à predisposição genética e a um gene autossômico recessivo ${ }^{7}$.

É mais frequente no sexo masculino e sua presença não influencia a expectativa de vida ${ }^{7}$.

Corpo estranho no intestino grosso pode ocorrer devido a ingestão ou introdução anal, podendo esta ser provocada por auto-erotismo, ataque criminoso, auto-administração para tratamento de doença anorretal ou após métodos diagnósticos feitos por via anal ${ }^{3,4,8}$.

A perfuração intestinal, devido ao seu grande potencial de complicações, é acompanhada de elevada morbidade e constitui-se em desafio aos cirurgiões.

Trabalho realizado no Serviço de Cirurgia do Hospital Geral do Estado (HGE) Osvaldo Brandão Vilela, Maceió, AL, Brasil.

Correspondência: André Vitório Câmara de Oliveira, e-mail: andrecirurgia@hotmail.com

\section{RELATO DO CASO}

J.C.S., masculino, 28 anos, deficiente mental, deu entrada no serviço de emergência proveniente do interior do Estado de Alagoas, com dor e distensão abdominal há sete dias, anorexia há dois, parada de eliminação de gases e fezes, sem vômitos. Ao exame apresentava dispnéia leve, desidratação $(++/ 4++)$, anictérico, $\mathrm{PA}=70 \mathrm{X} 40 \mathrm{mmHg}$, abdome tenso, difusamente doloroso, distendido e hipertimpânico, ruídos hidroaéreos ausentes. A radiografia de tórax evidenciou dextroversão cardíaca, pneumoperitônio bilateral e bolha gástrica à direita (Figura 1).

Devido ao estado geral grave e diagnóstico confirmado de abdome agudo perfurativo, o paciente não foi submetido a novos exames. Realizou-se reposição hidroeletrolítica venosa e foi submetido à celiotomia exploradora, onde evidenciou-se peritonite fecalóide difusa, fígado, cecum e apêndice cecal à esquerda, baço, cólon sigmóide e reto à direita, perfuração de cólon sigmóide por corpo estranho (garrafa plástica com cerca de $20 \mathrm{~cm}$ ) e necrose parcial de parede do sigmóide (Figura 2).

Realizou-se retirada do corpo estranho, limpeza mecânica, ampla lavagem da cavidade peritoneal, retossigmoidectomia à Hartmann e drenagem bilateral. Durante indução anestésica, iniciou-se o esquema antibiótico com metronidazol e ciprofloxacino, sendo mantido até a véspera da alta. 


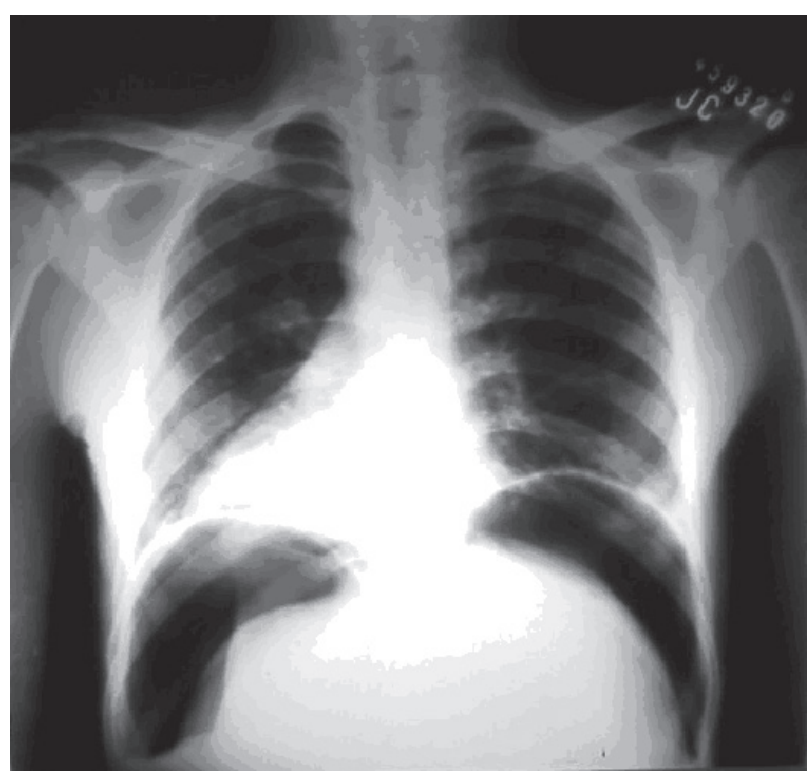

FIGURA 1 - Aspecto radiográfico do situs inversus totalis com inversão das imagens cardíaca e abdominais e pneumoperitôneo bilateral

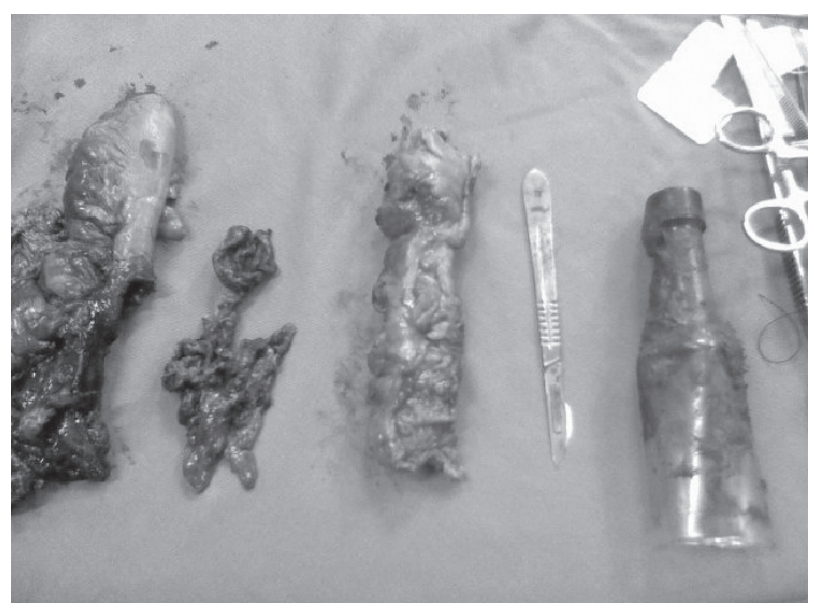

FIGURA 2 - Aspecto da peça operatória e corpo estranho

O paciente foi transferido para unidade de terapia intensiva, evoluiu com melhora do estado geral. Na enfermaria, apresentou pequena infecção na ferida operatória, que foi drenada. Recebeu alta hospitalar e foi encaminhado ao ambulatório.

\section{DISCUSSÃO}

O SIT geralmente não é identificado, já que não se opõe ao funcionamento normal do organismo. Consiste em embriopatia pouco frequente e de incidência variável segundo os autores. Nos Estados Unidos, a média foi de 0,00945\% e na Europa, 0,0087\%. Em média, chegou-se ao valor de 0,0093\%. No Brasil, Bertolazzo et al. ${ }^{2}$, ao analisarem 204 cadáveres adultos por período de sete anos consecutivos, encontraram SIT em apenas um cadáver (0.49\%) 2. Em pesquisa realizada por Melchor-Gonzáles et al. ${ }^{7}, 45 \%$ dos pacientes com SIT não tiveram a entidade identificada.

Corpos estranhos introduzidos no reto podem provocar perfurações no órgão e estruturas vizinhas, como vagina e bexiga. Mansur et al. ${ }^{6}$, relataram entre 1981 e 1990, a presença de 124 pacientes com trauma retal, e em 40\%, a introdução de corpo estranho no ânus foi a causa do traumatismo. Quando ocorre perfuração de retossigmóide, lesões de outros órgãos podem ocorrer, o que aumenta a taxa de morbidade.

O diagnóstico do corpo estranho no intestino grosso deve ser orientado pela história do paciente, exame abdominal, toque retal, exames radiológicos e endoscopia digestiva baixa. Como regra, os pacientes não confirmam a história de introdução, a não ser quando o corpo estranho fica retido. Em lugar desta, narram, sem constrangimento, acidentes fantásticos e excessivamente caprichosos ${ }^{3,6}$.

$\mathrm{O}$ tratamento dos pacientes com ferida de reto deve ser iniciado imediatamente, incluindo a profilaxia do tétano e a antibioticoterapia adequada para bactérias aeróbias Gramnegativas e anaeróbias. Embora não exista unanimidade em torno de conduta cirúrgica ideal, alguns procedimentos já podem ser assimilados como sendo de larga aceitação. A sutura da ferida do reto, a colostomia com lavagem do cólon distal e a drenagem pélvica, diminuíram significativamente a morbidade e a mortalidade desses pacientes ${ }^{1}$.

\section{CONCLUSÃO}

Apesar de ser entidade rara, o diagnóstico de SIT deve ser suspeitado durante o exame físico e confirmado através de exames de imagem, uma vez que as variações anatômicas podem prejudicar o desempenho clinicocirúrgico. 
Oliveira AVC, Maranhão CEC, Coelho CDS, Ferreira SLM, Tavares BNB, Barros LC. Perfurative acute abdomen due to foreign body in patient with situs inversus totalis. ABCD Arq Bras Cir Dig 2008;21(4): 215-7

ABSTRACT - Background - Situs inversus totalis is an important discovery for the conduct of clinical surgery. The foreign body in the large intestine can occur due to ingestion or anal introduction. The intestinal perforation is accompanied by high morbidity and becomes a challenge for the surgeons. Case report - Patient, male, 28 years old, mentally feeble, with pain and abdominal distension for seven days, anorexia for two days, no elimination of gas and feces, no vomiting. On the examination he showed mild dyspnea, dehydration $(++/ 4++)$, blood pressure $=70 \mathrm{X} 40 \mathrm{mmHg}$, anicteric, tense abdomen, diffusely painful, distended and hypertympanic, hydroaerial sounds absent. The thorax X-ray evidenced cardiac dextroversion, pneumoperitoneum bilaterally with gastric bubble on the right. Due to the general serious condition and confirmed diagnosis of acute abdomen perforation, a hydroelectrolytic vein replacement was held and the patient was submitted to an exploratory celiotomy, observing fecaloid diffuse peritonitis and perforation of sigmoid colon for foreign body taken away followed by mechanical cleaning, washing peritoneal cavity, Hartmann retossigmoidectomy, and bilateral drainage. Conclusion - Although a rare entity, the diagnosis of situs inversus totalis must be suspected in a physical examination and confirmed through image examinations, since the anatomic variations can disrupt the performance of clinical surgery.

HEADINGS - Situs inversus. Intestinal perforation.

\section{REFERÊNCIAS}

1. Accetta I, Accetta P, Queiro Filho CC, Silva HFA, Oliveira MAB. Feridas do reto (revisão de 40 casos). Rev. bras. Cir. 1987.77 (5):301-305.

2. Bertolazzo WR, Moreira \& cols A. Situs inversus totalis (heterotaxia total). Arq. bras. Med. 1984. 58(2): 94-96.

3. Cavichini QN, Sueth JRB, Tinoco, LA, Anderson PAV, Couto Júnior FC, Ciqueira NG; Ladeira GV. Corpo estranho no intestino grosso. Rev. bras. Colo-Proct. 1997. 17(4): 254-58.

4. d'Acampora AJ, Felício FS, Dos Santos JM, Fabiane C, Baldessar MZ. Corpo estranho de colo, reto e ânus. Arq. Cat. Med. 1988; 17: 23-27.

5. Elizondo ME, Etxabe JMU. Situs inversus totalis. Primera descripción científica realizada durante La llustración em México. Cirurgía Española. Vol.70, Noviembre 2001, Número 5 .
6. Mansur ES, Abrantes WL. Traumatismo de reto por corpo estranho: Estudo de 50 casos. Rev. bras. de coloproct. 1992: 12(2): 51-55.

7. Melchor-Gonzáles JM, Pèrez-Garcia R, Torres-Vista M, Rodriguez-Brambila VR. Situs inversus. Reporte de dos casos. Cirugía y Cirujanos 2000; 68: 72-75.

8. Santos JR JCM. Instrumentação Anal Erótica: Um Problema Médico-Cirúrgico. Rev bras Coloproct, 2007; 27(1): 096-100.

Fonte de financiamento: não há Conflito de interesse: não há Recebido para publicação: 22/06/2008 Aceito para publicação: 30/09/2008 